\title{
REFLEXÕES TEÓRICAS EM EDUCAÇÃO EM SAÚDE: GESTÃO DE ENFERMAGEM NA ATENÇÃO BÁSICA
}

Raissa Ribeiro da Silva; Josilene Nascimento do Lago;

Iris Araújo Gonçalves; Isis Araújo Gonçalves;

Adely Cristine Sales Campos

Discentes de Enfermagem da Universidade da Amazônia (UNAMA). E-mail: yllaribeiro@outlook.com

Rosineide Ribeiro da Costa Silva

Orientadora, Enfermeira, Especialista em Enfermagem em Terapia

Intensiva Adulta e Neonatal, Universidade do Estado do Pará

(UEPA). roseprincribeiro@gmail.com

\section{RESUMO}

Desde 2001, as diretrizes curriculares nacionais do curso de graduação em enfermagem (DCN/ENF), propõe mudanças emblemática no âmbito acadêmico, com intuito de formar profissionais habilidosos, críticos e comprometidos com a saúde da população. Além disso, possibita discutir o processo de formação, em suas múltiplas determinações e apreendê-lo na historicidade da educação em enfermagem no país. (FERNANDES e REBOUÇAS, 2013). De acordo com o Art. $2^{\circ}$ dessa Resolução, os princípios, fundamentos, condições e procedimentos da formação de enfermeiros, foram estabelecidas pela Câmara de Educação Superior do Conselho Nacional de Educação e a abordagem a importância de se ter nos currículos disciplinas de Administração Aplicadas à Enfermagem pela lei do Exercício Profissional - no 7498/86 que encarregou-se de trazer em sua assertiva atividades de planejamento, organização, coordenação, orientação e avaliação de serviços de enfermagem como sendo privativas do enfermeiro, dentre outras cujo responsabilidade é do atuante da área.

PALAVRAS-CHAVE: Educação em Enfermagem. Enfermagem. Gestão em Saúde. 


\begin{abstract}
Since 2001, the national curriculum guidelines for the undergraduate nursing course (DCN / ENF), have proposed emblematic changes in the academic field, with the aim of training skilled, critical and committed to the population's health. In addition, it makes it possible to discuss the training process, in its multiple determinations and apprehend it in the historicity of nursing education in the country. (FERNANDES and REBOUÇAS, 2013). In accordance with Article 2 of this Resolution, the principles, foundations, conditions and procedures for the training of nurses, were established by the Higher Education Chamber of the National Education Council and the approach to the importance of having Administration disciplines applied to the curricula Nursing by the Professional Exercise Law - $\mathrm{n}^{\mathbf{0}} 7498 / 86$, which was responsible for bringing in its assertive activities of planning, organization, coordination, guidance and evaluation of nursing services as being exclusive to the nurse, among others whose responsibility is the actuator of the area .
\end{abstract}

KEYWORDS: Nursing Education. Nursing. Health Management.

\title{
1 INTRODUÇÃO
}

Ao longo dos anos nas escolas de enfermagem, a formação esteve direcionada o atendimento das necessidades do paciente, de modo servil e automático, por conta da proibição da manifestação desses profissionais sentirem afeição diante do seu paciente. Sabe-se que esse tipo de conduta, acaba prejudicando a melhora das pessoas, mas em tempos passados os enfermeiros eram identificados como "anjos de branco", que deve riam ser bondosos, compreensíveis e afetuosos, e que seus problemas deviam ficar de fora do seu local de trabalho, afim de não atrapalhar sua função dentro do local de trabalho. Todo esse contexto não contribuiu para que a enfermagem desenvolvesse saberes sobre a relação interpessoal, dentre os conhecimentos, entre eles pode-se citar: a capacidade de escuta, comunicação e observação, que são competentes para uma excelente gerência. (SPAGNOL;SOARES;SILVEIRA, 2012).

Quanto a temática em questão, aborda-se sobre habilidades do profissional de enfemagem, e entre eles destacam-se quatro atividades de grande relevância: assistencial, gerencial, educativa e de pesquisa, onde nenhuma pode ser vivenciada separadamente, pois a interação existente é uma condição importante para assistência gerencial de enfermagem, para que não se acarrete riscos a população. No serviço de saúde, a enfermagem assume papel importante entre a equipe multidisciplinar, além da organicidade no decorrer do encargo, busca solidificar ações para serem realizadas juntamente aos clientes, para amparar as premências de saúde-doença tendo como guia de suas ações os direitos das pessoas que serão Complexitas - Rev. Fil. Tem., Belém, v. 4, n. 1, p. 73-78, jan./jun. 2019 - ISSN: 2525-4154 
atendidas,de forma humanizada, digna, segura e ética. (SPAGNOL, 2005). O objetivo do trabalho é relatar as vivências do acadêmicos de enfermagem diante da disciplina de gestão de enfermagem na atenção básica.

\section{METODOLOGIA}

A pesquisa refere-se a um relato de experiênca, que foi desenvolvido a partir do planejamento disciplinar, onde os conteúdos puderam ser trabalhados dinamicamente, estimulando o senso crítico e científico dos discentes. A disciplina é obrigatória, com carga horária de 60 horas, ministrada no $8^{\circ}$ semestre de 2019, aos acadêmicos de enfermagem, por uma docente da Universidade da Amazônia - UNAMA. Foram realizadas reuniões a cada 2 dias na semana, para planejar e aplicar a disciplina supracitada, anexo a isso incluiu-se, a organização das oficinas a serem prestadas, interação junto aos alunos, relatos pessoais em relação a disciplina, suas dificuldades e necessidades. O objetivo do conteúdo programático é pleitar a gestão, suas competências e habilidades na sistematização de circunstâncias ocasionadas pela gerência da equipe multidisciplinar.

Ademais, a docente focou, durante a disciplina, as aptidões associadas a segurança do paciente, onde a eficácia na comunicação e escuta, acolhimento e observação, estão destacadas como essenciais ao gerenciamento das organizações de saúde. Além disso, abordou sobre as metas atribuídas dentro dos hospitais, como cuidados com medicamentos de auto risco, garantia a cirurgia segura, redução dos riscos de infecção associadas aos cuidados em saúde, minimizar lesões por pressão e danos por queda no chão e o gerenciamento da equipe multidicipinar e de enfermagem em todas as proporções de aplicabilidade. Para desenvolver o assunto proposto, utilizaram-se os seguites recursos pedagógicos: recursos de exposições dialogadas, grupos de discussão, seminários, debates competitivos, apresentação e discussão de filmes e casos práticos e habilidades científicas e profissional.

Cada encontro para novos conhecimentos contribuiu com a interação e com a necessidade de compartilhar experiências através de amostras científicas, por conta disso foi proposto como metodologia avaliativa da disciplina, a construção de uma obra científica motivando a exploração, na visão dos discentes de enfermagem, as capacidades e valências fundamentais para gerir pessoas. A oportunidade ocasionou a realização de oficinas pedagógicas efetivadas pelos discentes, exposição de dramatização e simulação realística da 
vivência do enfermeiro, exposição de trabalhos manuais como tecnologia de fácil aprendizado ao paciente, uso de tecnologias leves como produção de cuidado em saúde, além da exposição de trabalhos relacionados a musicoterapia, palhaçaria hospitalar, como aplicação no ensino de pacientes e da equipe multidiciplinar.

\section{RESULTADOS E DISCUSSÃO}

Os resultados foram interpretados e discutidos a partir das estratégias pedagógicas desenvolvidas em duas etapas durante o semestre, que tiveram a finalidade de encorajar os discentes a vivenciarem os conhecimentos sobre o gerenciamento de enfermeiros na atenção básica. Na primeira etapa, foram abordados as seguites temáticas: Gestão em atenção básica à saúde e enfermagem; As políticas de saúde e a gestão na atenção básica à saúde; O perfil do enfermeiro gestor na atenção básica à saúde. Diante dessa etapa, os acadêmicos mostravam-se apreensivos, ansiosos e com dificuldades diante dos assuntos abordados. Incluso a isso, podese afirmar que academia de enfermagem dá suporte ao discente, porém nem todos conhecem sobre as problemáticas relacionadas as temáticas em questão, tendo em vista essa dificuldade foi atribuído a metodologia supracitada em prol do estímulo a práticas pedagógicas em saúde.

Após às inúmeras indagações sobre os temas, todos relataram estar compreendendo o contexto em questão, devido a uma abordagem com uso de vocabulário mais dinâmico e de fácil entendimento, resultando na constante participação e resultados positivos mediante a ordenação dos temas. A segunda etapa, direcionou-se para outra abordagem nos conteúdos, onde envolveu o processo de enfermagem na atenção básica à saúde e gerenciamento de materiais, território, área, microárea e modelos tecno-assistencias em saúde. Nessa etapa, foi possível observar o desconhecimento de alguns discentes em relação ao processo de enfermeiro como gerente, mediate a esta ocorrência a docente desenvolveu uma escuta capaz de captar as dúvidas dos discentes e propiciar uma análise reflexiva das relações entre a teoria e a prática profissional, a fim de esclarecer possíveis dúvidas.

\section{CONSIDERAÇÕES FINAIS}

As mudanças possibilitadas pela disciplina, não ocorreram apenas no ambiente de sala de aula, pois o conhecimento foi disseminado através de publicações de trabalhos, externalização de conhecimentos as pessoas que habitam a Universidade. Conduziu-se os alunos a buscar novos projetos em relação a gestão. As ações relizadas constatam que o método pedagógico aplicado a disciplina de gestão de enfermagem na atenção básica, permitiu Complexitas - Rev. Fil. Tem., Belém, v. 4, n. 1, p. 73-78, jan./jun. 2019 - ISSN: 2525-4154 
aos alunos uma vivência teórico-prático. As mesmas influenciaram na procura criativa e proativa de conhecimentos, além de propiciar a busca de promoção da saúde, remodelação de informação, sondando a empatia entre pessoas e suas vivências, fortalecendo conhecimentos para que um todo exceda os obstáculos e tenha a liberdade na tomada de escolhas enquanto ser elementar na gerência do seu ambiente de trabalho.

Constatamos que é de fundamental importância que se intensifiquem as metodologias pedagógicas que provoquem e estímulem os discentes a ter interesse sobre gestão, que as etapas de experimentação e vivência de aprendizagem ul trapassem a universidade e estejam presentes nos dias dos futuros profissionais que se tornarão. Assim, haverão ápices de reflexão sobre as didáticas propostas e sobre as práticas desenvolvidas, oportunizando o engrandecimento no saber-fazer do profissional de enfermagem.

\section{REFERÊNCIAS BIBLIOGRÁFICAS}

BRASIL, Conselho Nacional de Educação. Diretrizes curriculares nacionais do curso de graduação em enfermagem. Resolução CNE/CES 3/2001. Diário Oficial da União, 9 de Novembro de 2001. Seção 1, p. 37. Disponível em: acesso em: 03 set 2019.

FERNANDES, Josicelia Dumêt; REBOUCAS, Lyra Calhau. Uma década de diretrizes curriculares nacionais para a graduação em enfermagem: avanços e desafios. Revista brasileira de enfermagem. Brasília, v.66, n.spe, p.95-101, Set. 2013. Disponivél em: http://www.scielo.br/scielo.php?scr ipt=sci_arttext\&pid=S0034-716 72013000700013. Acesso em: 05 Set. 2019.

SPAGNOL, Carla Aparecida. (Re)pensando a gerência em enfermagem a partir de conceitos utilizados no campo da saúde coletiva. Ciência saúde coletiva, Rio de Janeiro, v.10, n.1, p.119127, Mar. 2005. Disponível em: http://www.scielo.br/pdf/csc/v10n1 I a13v10n1.pdf. Acesso em: 03 Set. 2019.

SPAGNOL, Carla Aparecida.; SOARES, Amanda Nathale.; SILVEIRA, Vieira Silveira. Experiências pedagógicas vivenciadas na disciplina competências e habilidades para gestão de pessoas nas organizações de saúde. Revista Enfermagem do Centro Oeste Mineiro 2012 set/dez; v.2, n.3 p.451-462. Disponível em: http://www.seer.ufsj.edu.br/index.p hp/recom/ article/viewFile/246/359. Acesso em: 05 Set. 2019 
SILVA, R.R., LAGO, J. N., GONÇALVES, I. A., GONÇALVES, I.A., CAMPOS, A. C. S., SILVA, R.R.C. Reflexões Teóricas em Educação em Saúde: Gestão de Enfermagem na Atenção Básica.

Complexitas - Rev. Fil. Tem. Belém, v. 4, n. 1, p. 73-78, jan./jun. 2019. Disponível em: http://www.periodicos.ufpa.br/index.php/complexitas/article/view/8046>. Acesso em: 30 de janeiro de 2020. 